\title{
A Rare Case of Rectovaginal Fistula Due to Consensual Sexual Intercourse
}

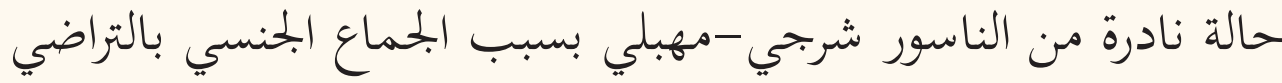

$$
\text { فداء العسلي، رامي كيلاني، فراس رشود، إسماعيل أبو محفوظ }
$$

ABSTRACT: Rectovaginal fistulae after sexual intercourse are rare. We report a healthy recently married 21-year-old woman who presented to the Jordan Healthcare Centre, Amman, Jordan in 2014 with a five-week history of passing flatus and stool from the vagina. Six weeks prior, she had sustained a rectovaginal injury during initial consensual sexual intercourse, leading to the development of a distal rectovaginal fistula. A successful transvaginal repair was performed nine weeks after presentation which resulted in the complete resolution of her symptoms.

Keywords: Rectovaginal Fistula; Sexual Intercourse; Dyspareunia; Case Report; Jordan.

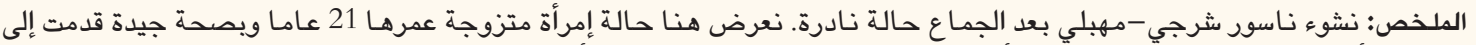

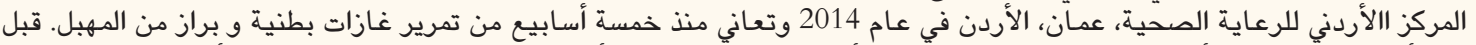

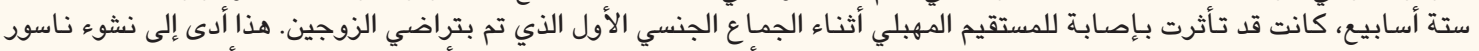

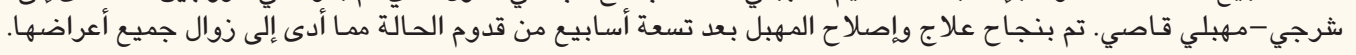

$$
\begin{aligned}
& \text { الكلمات المفتاحية: ناسور شرجي-مهبلي؛ الجماع الجنسي؛ عسر الجماع؛ تقرير حالة؛ الأردن. }
\end{aligned}
$$

\section{$\mathrm{M}$} ILD GENITAL INJURIES DURING CONSENSUAL sexual intercourse are not uncommon and are usually associated with minor bleeding; Abasiattai et al. reported that genital injuries related to sexual intercourse accounted for 0.7 out of 1,000 gynaecological emergencies in Calabar, Nigeria. ${ }^{1}$ Worldwide, the most common causes of rectovaginal fistulae (RVF) are obstetric, followed by cervical cancer, radiation injuries, inflammatory bowel disease, operative gynaecological trauma and rectal cancer. ${ }^{2}$ However, the development of RVF after sexual intercourse is rare, with only 91 cases related to both consensual sexual intercourse and rape reported between 1991 and 1997 at the Addis Ababa Fistula Hospital in Ethiopia. ${ }^{3}$

\section{Case Report}

A healthy 21 year-old woman presented to the Gynaecology Clinic of the Jordan Healthcare Centre, Amman, Jordan in 2014 with a five-week history of passing flatus and stool from the vagina. She had gotten married six weeks prior to presentation and had had sexual intercourse twice on her wedding night. During the first act, she noted mild pain and vaginal bleeding; however, the second time, penetration of the vagina was difficult and much more painful. This second act of penetration was immediately followed by heavy vaginal bleeding. The following day, she consulted her gynaecologist and a vaginal examination showed a distal posterior vaginal wall laceration. She was reassured and prescribed oral antibiotics. However, the patient began to notice the passage of flatus and stool from the vagina one week later. She therefore sought a second opinion from another gynaecologist. At this time, the vaginal examination showed an RVF measuring around $2.5 \mathrm{~cm}$. Both the gynaecologist and a general surgeon advised conservative management, including oral antibiotics, stool softeners and perineal care.

Subsequently, the patient presented to the Jordan Healthcare Centre six weeks after the incident. She described little improvement in her symptoms and felt that the condition was seriously affecting her psychological wellbeing. An examination showed a scarred deficient perineum measuring $1.5 \mathrm{~cm}$, with right lateral vaginal wall scar tissue at the 8 o'clock position. The opening of the fistula was clearly visualised in the distal posterior vaginal wall, traversing in a longitudinal direction and measuring approximately $0.5 \times 2 \mathrm{~cm}$. The distal edge of the RVF was around $0.5 \mathrm{~cm}$ proximal to the hymenal ring and the vaginal skin surrounding the tract was inflamed. A rectal examination showed a $2 \mathrm{~cm}$ distal fistula, with good anal sphincter tone. Unfortunately, it was not possible to objectively evaluate the anal sphincter due to the lack of endoanal 
ultrasonography equipment. The skin surrounding the fistula tract was infected.

Following a detailed consultation, the patient requested that the RVF be surgically repaired as soon as possible, despite medical advice to continue conservative management for another few weeks. Nevertheless, she agreed to take oral antibiotics to treat the infection and to continue taking stool softeners. At a follow-up visit two weeks later, the infection was found to have resolved. The planned transvaginal repair was scheduled a week later and the patient underwent preoperative bowel preparation. Intraoperatively, the posterior vaginal wall and perineal skin were incised, the vaginal wall was reflected, the RVF was isolated and the edges of the tract were excised. Using fine delayedabsorbable sutures, the rectum was closed, followed by a two-layer closure of the endopelvic fascia. The perineum was then reconstructed and the vaginal skin closed.

The following morning, the patient was discharged and prescribed a two-week regimen of stool softeners and oral antibiotics. She attended follow-up appointments every two weeks for a total of eight weeks. Nine weeks after the surgery, a vaginal and rectal examination showed that the RVF had healed and the patient was able to resume sexual intercourse. She reported no dyspareunia or recurrence of the fistula-related symptoms. She subsequently became pregnant twice, with the first pregnancy occurring six months after the repair. She delivered both babies by elective Caesarean section at 39 gestational weeks.

\section{Discussion}

Risk factors for developing an RVF after sexual intercourse include young patient age, rough coitus, the first act of penetrative sexual intercourse, penovaginal disproportion and intercourse during the puerperium period. ${ }^{4}$ In the current case report, the patient was believed to have sustained a traumatic rectovaginal injury during her first act of sexual intercourse. As well as rupturing the hymen, this likely caused a laceration in the distal part of the posterior vaginal wall which subsequently acted as a weak entry point for the penis to pass through the vaginal wall during the second act of intercourse, thus resulting in the RVF. This may have been compounded by particularly hard thrusts on the part of an over-eager husband and the contracture of the patient's pelvic muscles in response to the pain. Considering its presentation shortly after the initial act of intercourse, direct rectovaginal trauma was deemed the most probable cause of RVF in this patient; however, vascular injury and infection may also have been contributing factors.
In the current case, the traumatic RVF was an isolated injury and was easily diagnosed on a clinical basis, with no need for any further specific investigations. However, various other diagnostic modalities may be useful in evaluating patients with suspected fistulae, such as a colonoscopy, barium enema, computed tomography or magnetic resonance imaging. ${ }^{5}$ An anorectal ultrasound scan can also be used to check the integrity of the anal sphincter. If diagnosed early, traumatic RVF should be treated surgically. ${ }^{5}$ However, infected fistulae or those of infective origin require initial medical care. Conservative management includes perineal care, the drainage of any abscesses, antibiotic therapy to treat the infection and stool softeners to regulate bowel function. ${ }^{5}$ If a fistula has not healed completely after 6-12 weeks of conservative treatment, then surgical repair should be considered. ${ }^{6}$

The surgical repair of an RVF may be performed either locally (i.e. transrectal or transvaginal repairs) or transabdominally. ${ }^{5}$ Prior to surgery, mechanical bowel preparation and intravenous antibiotics are essential. Currently, the vast majority of fistulae are repaired without the need for a preoperative colostomy. ${ }^{5}$ When considering local repair, either transanal advancement flaps or transvaginal repairs are used. Transabdominal repairs are generally used for high fistulae resulting from inflammatory bowel disease, cancer or radiotherapy. ${ }^{5}$ The simplest abdominal approach involves division and closure of the fistula without bowel resection; however, the latter may be necessary in cases of radiation damage or cancer. A simple faecal diversion with an ileostomy or colostomy may be necessary in patients with high operative risk or individuals who do not have a long life expectancy. ${ }^{5}$ While the patient in the present case presented early to a healthcare facility, the diagnosis was unfortunately delayed due to an incomplete clinical evaluation. It is possible that a thorough examination would have helped ensure earlier diagnosis and treatment.

There are limited reports about reproductive performance and managing delivery among pregnant women following the successful repair of a genital fistula. In 1974, Aimakhu reported that 20\% of women with obstetric traumatic vesicovaginal fistulae who had had a successful repair went on to have a term pregnancy. ${ }^{6}$ While several researchers have indicated that the optimal mode of delivery after the successful repair of an obstetric fistula is an elective Caesarean section, the evidence for this approach is limited. ${ }^{7,8}$ However, among women with successfullyrepaired obstetric fistulae who were allowed to deliver vaginally, 55\% had their fistulae opened during delivery. ${ }^{9}$ In the current case, the patient became pregnant twice and successfully delivered both times via elective Caesarean section. 


\section{Conclusion}

Female genital injuries after consensual sexual intercourse are rare. However, if serious, such injuries can have a negative impact on a woman's health and quality of life. In cases of traumatic RVF, a thorough and timely physical examination may help avoid any unnecessary delays in treatment.

\section{ACKNOWLEDGEMENTS}

The authors would like to thank Mr. Salem A. Mahfouz for his contributions in the preparation of this manuscript for publication.

\section{References}

1. Abasiattai AM, Etuk SJ, Bassey EA, Asuquo EE. Vaginal injuries during coitus in Calabar: A 10-year review. Niger Postgrad Med J 2005; 12:140-4.

2. Abu Gazala M, Wexner SD. Management of rectovaginal fistulas and patient outcome. Expert Rev Gastroenterol Hepatol 2017; 11:461-71. doi: 10.1080/17474.124.2017.1296355.
3. Ekwempu CC. Fistulae. In: Agboola A, Ed. Textbook of Obstetrics \& Gynaecology for Medical Students. Ibadan, Nigeria: Heinemann Educational Books, 1988. Pp. 46-59.

4. Amenu D. Rectovaginal fistula in a newly-married woman. Gynecol Obstet (Sunnyvale) 2015; 5:296. doi: 10.4172/21610932.1000296

5. Vogel JD, Johnson EK, Morris AM, Paquette IM, Saclarides TJ, Feingold DL, et al. Clinical practice guideline for the management of anorectal abscess, fistula-in-ano, and rectovaginal fistula. Dis Colon Rectum 2016; 59:1117-33. doi: 10.1097/DCR.000000 0000000733.

6. Aimakhu VE. Reproductive functions after the repair of obs-tetric vesicovaginal fistulae. Fertil Steril 1974; 25:586-91. doi: 10.1016/S0015-0282(16)40514-5.

7. Browning A, Menber B. Women with obstetric fistula in Ethiopia: A 6-month follow up after surgical treatment. BJOG 2008; 115:1564-9. doi: 10.1111/j.1471-0528.2008.01900.x.

8. Browning A. Pregnancy following obstetric fistula repair, the management of delivery. BJOG 2009; 116:1265-7. doi: 10.11 11/j.1471-0528.2009.02182.x

9. Emembolu J. The obstetric fistula: Factors associated with improved pregnancy outcome after a successful repair. Int J Gynaecol Obstet 1992; 39:205-12. doi: 10.1016/0020-7292(92) 90658-6. 